\title{
Stable endemic malaria in a rainforest community of Southeastern Nigeria
}

\author{
Ugha, C.N., Onyido, A.E., Obiukwu, M.O., Umeanaeto, P.U., Egbuche, M.C. \\ and Obiechina, I.O. \\ Department of Parasitology and Entomology, Nnamdi Azikiwe University, P.M.B. 5025 Awka, Anambra State, \\ Nigeria
}

\begin{abstract}
Malaria infections in a stable endemic malaria community of Abagana, a rainforest community in southeastern Nigeria was studied between April and August 2012. Advocacy visits to the traditional ruler and opinion leaders of the community and proper explanations of the project were used to obtain permission to carry out the study. The community was mobilized through public announcements in the churches, schools, markets and group meetings. Thick and thin blood films were used to concentrate, and identify malaria parasites using oil immersion lense of bright field light microscope. Estimates of parasite intensity per person was made on each positive slide by parasite count in the microscope fields. Participants were grouped into sexes, age, education and occupation. A total of 141 participants made up of 59(41.84\%) males and 82(58.16\%) females were involved in the study. Of the 141 participants, $76(53.90 \%)$ were positive with malaria parasites, among whom 32(42.11\%) were males and 44(57.89\%) were females. Of the positive malaria cases, malaria intensity among the participants were light 32(42.11\%), moderate 35(46.05\%) and heavy 9(11.84\%) and was spread across all the groups and villages. These results revealed holoendemicity of malaria in the community. Intervention efforts including massive educational campaigns were suggested.
\end{abstract}

Keywords- Endemic,holoendemicity, intensity, parasite,rainforest

\section{Introduction}

Malaria is an infectious disease that torments primarily the tropical and subtropical areas of the world. It is the most important and widespread human parasitic disease [1] and is one of the leading causes of morbidity and mortality worldwide [2]. Every year, between 300 to 500 million clinical cases of malaria, accounting for over one million deaths are recorded globally [3]. Over $90 \%$ of all cases of malaria occur in Africa, South of the Sahara [4]. In the endemic areas of the world, children under the age of five years and women in their first pregnancy are most vulnerable to the disease [5].

In Nigeria, malaria is a major public health problem. It results in $25 \%$ infant and $30 \%$ childhood mortality and about $50 \%$ of the 150 million people of Nigeria suffer at least one episode of malaria each year [6]. The Federal Ministry of Health [7] reports that one in four people suffer from malaria fever at one time or the other while up to 1.2 million children (under the age of five years) still die of malaria annually, and the numbers affected are growing remorselessly [8]. Malaria is holoendemic in rural areas and mesoendemic in urban centres. The disease accounts for $40 \%$ of public health expenditure, $30-50 \%$ of in-patient admissions and upto $50 \%$ out patients with high transmission [9].

The economic burden of malaria illness in malaria households account for almost $50 \%$ of the total economic burden of illness in malaria holoendemic communities [10]. Also, the presence of malaria in a community is considered to hamper both individual and national developments due to loss of lives and useful manhours as well as absenteeism in schools and workplaces [11].

Malaria transmission in Nigeria is epidemic and strongly seasonal for 1-3 months in the Sahel savannah zone, endemic and seasonal for 4-6 months in Guinea savannah zone and endemic and perennial in the rain and mangrove forest zone [7]. In a three months prospective study to investigate the seasonal variations in episodes of malaria among 20 patients attending a community Health Centre at Udi, Enugu State, Nigeria, [12] obtained a statistically significant higher number of episodes of malaria in wet season than in dry season. In the same study, the author also obtained a perfect positive correlation between episodes of malaria and gametocytopaenia in wet than in dry season indicating a higher rate of malaria transmission in wet season in the presence of mosquito vectors.

This study was therefore aimed at studying the malaria burden at Abagana community in the rainforest zone of Nigeria so as to provide baseline data for the effective control of malaria and other mosquito-borne diseases in the area. The specific objectives were to determine the prevalence of malaria infections in Abagana community, and the groups (age, sex, occupation and education) mostly at risk in the area. 


\subsection{Study area}

\section{Materials and methods}

Abagana town is between Onitsha and Awka metropolis, the capital city of Anambra State of Nigeria. It has geographical co-ordinates of approximately $6^{\circ} 14^{\prime} \mathrm{N}$ and $6^{\circ} 18^{\prime} \mathrm{N}$ North latitude and $7^{\circ} 50^{\prime} \mathrm{N}$ and $7^{\circ} 09^{\prime} \mathrm{E}$ East longitude. It is located in the tropical rainforest zone of southeastern Nigeria, although it has derived savanna vegetation due to increased human activities. It has two marked seasons, the dry and wet seasons. There are about 8 months (April - November) of wet season and four months (November - March) of dry season. It has a relative humidity of $70 \%$ reaching $80 \%$ during rainy season and an annual rainfall of about $2000-3000 \mathrm{~mm}$ [13].The daily temperature ranges from $26^{\circ} \mathrm{C}-36^{\circ} \mathrm{C}$ during the dry season stretching from November to March, and from $22^{\circ} \mathrm{C}-32^{\circ} \mathrm{C}$ during the wet season stretching from April to November.

The town is made of up of six villages; Adagbe, Akpu, Amaenye, , Orofia, Umudunu, Uruokpala and has a population of 105,000 inhabitants [14]. Most houses in the community are built of concrete walls with corrugated iron roofing sheets although there are still a few mud and thatched houses around. Abagana is supplied with a good network of laterite roads except for a few that are tarred especially the major road that connects Onitsha to Awka.

Abagana has a government-owned Health Centre that serves the neigbouring communities. It has a good network of electricity supply, five secondary schools and more than fifteen primary schools.

The inhabitants are mainly Igbos. Occupationally, the indigenes are itinerant traders, craftsmen and farmers. With the creation of Anambra State in 1991, and the establishment of Government machineries and institutions of higher learning, about $60 \%$ of the population are civil servants and students while the remaining $40 \%$ are farmers, traders and other occupations. Domestic water supplies are from streams running across the community and many small springs though some parts of the community make use of boreholes as their domestic water sources.

The largest stream is the Ngene Egbedani stream at Adagbe village, flowing down from Eziowelle, running through Enugwu-Ukwu, Nimo and Neni.

\subsection{Community mobilization}

Advocacy visits to the traditional ruler and opinion leaders of the community and proper explanations of the project intent were used to obtain permission to carry out the studies in the community. The community was mobilized through public announcements in the churches, schools, markets and town criers. All the participants were assembled at the civic centre on an agreed date. The project intent was again explained to the community at large. In addition, the demographic data of each participant were also collected.

\subsection{Collection of blood sample}

Blood samples for the study were collected through venepuncture technique [15]. Soft tubing tourniquet was fastened to the upper arm of the participant to enable the index finger feel a suitable vein. The puncture site was cleaned with methylated spirit (methanol) and venepuncture made with the aid of a $21 \mathrm{~g}$ needle attached to a $5 \mathrm{ml}$ syringe. $1 \mathrm{ml}$ of blood was collected from each patient, the tourniquet was released and the needle removed immediately while the blood was transferred into an EDTA treated bottle [15].

\subsection{Thick blood film preparation and staining}

Each thick blood film was prepared by dropping three drops of the blood sample at the centre of a clean grease-free microscope glass slide and spread in a circular motion using the edge of another clean slide until it became transluscent. The preparations were air-dried and stained according to the method described by [16] using Field's stain.

\subsection{Thin blood film preparation}

Thin blood films were prepared by placing a drop of blood at about two thirds length of a clean dry slide. A clean smooth edged spreader, was drawn back to touch the drop of blood and to allow the blood to extend along the edge of the spreader. Holding the spreader at an angle of about $45^{\circ}$, the blood was spread by firm and gentle push to the far end of the slide to make a film of about $40-50 \mathrm{~mm}$ in length. The end of the spreader was wiped clean to avoid 'holes' in the blood film. The film was air-dried by waving the slide back and forth in the air. After it was fixed in absolute methanol and stained with Field's stain [16].

\subsection{Microscopy and parasite identification}

Immersion oil was dropped at the centre of each film. Each slide was examined under the microscope using $\mathrm{x} 40$ and $\mathrm{x} 100$ objectives. Malaria parasites identification was undertaken based on species specific characteristics and other morphological features with respect to size and shape of the infected red blood cells, chromatin dots, patterns of ring form trophozoites, number of rings per red blood cells and shape and features of schizonts and gametocytes [17]. 


\subsection{Statistical analysis of data}

Data obtained in the studies were analysed using Social Sciences Statistical Package (SPSS), version 17.0. Cross tabulations were generated and Chi- square and ANOVA tests were applied for analysis [18].

\subsection{Estimation of parasite intensity}

Estimates of parasite intensity was made on each positive slide by parasite count. The intensity of parasitaemia was graded low, moderate, and heavy, based on the number of parasites detected per high power field of the light microscope as follows:

Low $(+)=1-10$ parasites per 100 high power field

Moderate $(++)=1-100$ parasites per 100 high power field

Heavy $(+++)=1-10$ parasites in every high power field

\section{Results}

A total of 141 participants from the six villages of Abagana comprising 59(41.84\%) males and $82(58.16 \%)$ females, were involved in the study (table 1). Between 15(10.64\%) and 33(23.40\%) participants came from the different villages of the community. The least number of participants $15(10.64 \%)$ were from Uruokpala village while the highest number 33(23.40\%) were from Akpu village. There was no significant difference in the number of participants from the different villages $(\mathrm{P}>0.05)$. The male participants from the villages constituted between $8(38.09 \%)$ and $9(47.37 \%)$ while the females were between $10(52.63 \%)$ and $13(61.90 \%)$. More females than the males came from all the villages of the community. There was no significant difference in the numbers of males and females that participated in the study $(\mathrm{P}>0.05)$.

The participants were subdivided into fourteen age groups of five years interval each. The highest number of participants 20(14.18\%), were from the age group 36 - 40years, while the least number 2(1.42\%), were from the age group $71-75$ years. The males varied in numbers from $1(20.00 \%)$ in the age group $41-50$ years to $2(50.00 \%)$ in the age group $61-65$ years. The females varied from $8(44.44 \%)$ in the age group $16-20$ years to $7(70.00 \%)$ in the age group $31-35$ years. With the exception of the age group $16-20$ years, where there were more males $10(55.56 \%)$ than the females $8(44.44 \%)$, more females than the males were from the other age groups.

Four occupational groups namely; civil servants, traders, students and applicants participated in the study. The traders constituted the highest number of participants $48(34.04 \%)$ while the applicants $21(14.89 \%)$, were the least. The males from the different occupational groups were between 11(36.67\%) among the civil servants and 11(52.38\%), among the applicants. The females were between 10(47.62\%) among the applicants and $19(63.33 \%)$ among the civil servants. Male applicants $11(52.38 \%)$ were slightly higher than the females $10(47.62 \%)$. More females than the males came from other occupational groups.

Three educational groups; primary, secondary and tertiary, were identified among the study participants. The primary education group had the highest number of participants $67(47.52 \%)$ while the tertiary education group had the least number $25(17.73 \%)$. The number of participants from primary education group was significantly higher than those of secondary and tertiary education groups $(\mathrm{P}<0.05)$. In all the educational groups, the males varied from $25(37.31 \%$ ) among the primary education group to $24(48.98 \%)$ among the secondary education group while the females were between 25(51.02\%) and 42(62.69\%). More females than the males were from all the educational groups.

Four marital groups viz: married, singles, divorced and widows/widowers, participated in the study. The married group 47(33.33\%), had the highest number of participants while divorcees were the least $26(18.44 \%)$. The males from different marital groups varied in numbers from 11(37.93\%) among the widow/widowers to $12(46.15 \%)$ among the divorcees. More females than the males were from the four marital groups.

Of the 141 participants in the study, 76(53.90\%) were positive with malaria parasites, among whom $32(42.11 \%)$ were males and 44(57.89\%) were females (table 2). There was no significant difference in malaria prevalence between the males and females $(\mathrm{P}<0.05)$, although slightly more females than the males were positive with malaria parasites.

Malaria infection was observed in all the villages of Abagana community. The highest prevalence of $10(66.67 \%)$ occurred in Uruokpala village while the least prevalence of $8(38.09 \%)$ was in Orofia village. Malaria prevalence in Uruokpala, Adagbe, Amaenye and Akpu villages were significantly higher than those of Orofia and Umudunu $(\mathrm{P}<0.05)$. An equal prevalence of $66.67 \%$ was observed among the males and females from Uruokpala village. More males than the females were positive with malaria parasites at Akpu, Amaenyi and Umudunu villages while more females than the males were infected with malaria at Adagbe and Orofia villages. 
Malaria infections occurred in all the age groups examined and the prevalence varied between $5(26.32 \%)$ in the age group $26-30$ years, and $10(90.91 \%)$ among those aged $0-5$ years. There was a significant difference in malaria prevalence among the age groups examined $(\mathrm{P}<0.05)$.

Malaria infection was also observed in all the occupational groups. The highest malaria prevalence of $13(61.90 \%)$ was recorded among the applicants while the least $12(40.00 \%)$ was among the civil servants. There was a significant difference in malaria prevalence among the four occupational groups examined $(\mathrm{P}<0.05)$. More males than the females among the traders and students were infected with malaria parasites while more females than the males among the applicants and civil servants had malaria infection.

All the educational groups had malaria infections and the prevalence varied from 11(44.00\%) among the tertiary education group to $39(58.21 \%)$ among the primary education group. Malaria prevalence was significantly higher among the primary and secondary education groups than the tertiary education group $(\mathrm{P}<0.05)$. More males $16(64.00 \%)$ than the females $23(57.14 \%)$ among the primary education group had malaria while more females than the males among the secondary and tertiary education groups were infected.

Malaria infection was also observed among the different marital groups. The prevalence varied from $17(36.17 \%)$ among the married groups living together to 22(75.86\%) among the widows and widowers. Among the singles and the divorced, more females than the males were positive with malaria while more males than the females had malaria among the married and widows/widowers. Malaria prevalence was significantly less among the married couples living together and the singles than among the divorced and the widow/widowers $(\mathrm{P}<0.05)$.

Of the 76 positive malaria cases observed in Abagana community, 32(42.11\%) were light infections with 1 - 10 parasites per 100 high power fields, 35(46.05\%) were moderate infections with $11-100$ parasites per 100 higher power fields and $9(11.84 \%)$ were heavy infections with more than 10 parasites for every high power field observed (table 3 ). The light infections ranged from 2(25.00\%) in Umudunu village to $8(47.06 \%)$ in Adagbe village. Moderate infections ranged from 3(37.50\%) in Orofia village to 5(62.50\%) in Umudunu village while heavy infections varied from 1(7.69\%) in Amaenye village to 2(25.00\%) in Orofia village.

Among the age groups, light infections ranged from $3(30.00 \%)$, in the age group $0-5$ years to $4(66.67 \%)$ in the age group $16-20$ years . Moderate infections were from 2(33.33\%) in the age group $16-20$ years to $3(75.00 \%)$ in the age group $21-25$ years. Heavy infections were from $1(12.50 \%)$ in the age group 6 10 years to $1(50.00 \%)$ in the age group $71-75$ years. There was a significant difference in malaria intensity among the fourteen age groups examined $(\mathrm{P}<0.05)$.

Light and moderate malaria infections were observed in all the occupational groups. Heavy infection was not observed among the civil servants. Light infections were from 3(23.08\%) among the applicants to $7(58.33 \%)$ among the civil servants. Moderate infections ranged from $10(40.00 \%)$ among the students to $7(53.85 \%)$ among the applicants. Heavy infections was not observed among the civil servants but it was $3(23.08 \%)$ among the applicants. There was a significant difference in malaria intensity among the four occupational groups examined $(\mathrm{P}<0.05)$.

Light, moderate and heavy infections were observed among all the educational groups. Light infections varied from $15(38.46 \%)$ among the primary education group to $12(46.15 \%)$ among the secondary education group. Moderate infection varied from 4(36.36\%) among the tertiary education group to 20(51.28\%) among the primary education group. Heavy infection was highest $2(18.18 \%)$ among the tertiary education group and least $4(10.26 \%)$ among the primary education group. There was a significant difference in malaria intensity among the three educational groups examined $(\mathrm{P}<0.05)$.

The percentage of people with light infections varied from 6(27.27\%) among the widows/widowers to $10(55.56 \%)$ among the divorcees. Those with moderate infections ranged from 6(33.33\%) among the divorcees to $12(54.55 \%)$ among the widows/widowers. Heavy infections were least $4(5.88 \%)$ among the married couples living together and highest $4(18.18 \%)$ among the widows/widowers. There was a significant difference in malaria intensity among the four marital groups examined $(\mathrm{P}<0.05)$.

Table 1. Personal data of the study participants from Abagana community.

\begin{tabular}{|c|c|c|c|c|}
\hline & ersonal data & No. examined (\%) & No. males (\%) & No. females (\%) \\
\hline \multirow{7}{*}{ A. } & Village & & & \\
\hline & Adagbe & 30 (21.28\%) & $13(43.33 \%)$ & $17(56.67 \%)$ \\
\hline & Akpu & $33(23.40 \%)$ & $13(39.39 \%)$ & $20(60.61 \%)$ \\
\hline & Amaenye & $23(16.31 \%)$ & $10(43.48 \%)$ & $13(56.52 \%)$ \\
\hline & Orofia & $21(14.89 \%)$ & $8(38.09 \%)$ & $13(61.90 \%)$ \\
\hline & Umudunu & $19(13.48 \%)$ & $9(47.37 \%)$ & $10(52.63 \%)$ \\
\hline & Uruokpala & $15(10.64 \%)$ & $6(40.00 \%)$ & $9(60.00 \%)$ \\
\hline
\end{tabular}




\begin{tabular}{|c|c|}
\hline Total & 141 \\
\hline
\end{tabular}

B. Age group

$\begin{array}{cccc}0-5 & 11(7.80 \%) & 4(36.36 \%) & 7(63.64 \%) \\ 6-10 & 12(8.51 \%) & 5(41.67 \%) & 7(58.33 \%) \\ 11-15 & 13(9.22 \%) & 5(38.46 \%) & 8(61.54 \%) \\ 16-20 & 18(12.77 \%) & 10(55.56 \%) & 8(44.44 \%) \\ 21-25 & 15(10.64 \%) & 6(40.00 \%) & 9(60.00 \%) \\ 26-30 & 19(13.48 \%) & 9(47.37 \%) & 10(52.63 \%) \\ 31-35 & 10(7.09 \%) & 3(30.00 \%) & 7(70.00 \%) \\ 36-40 & 20(14.18 \%) & 7(35.00 \%) & 13(65.00 \%) \\ 41-50 & 5(3.55 \%) & 2(40.00 \%) & 3(60.00 \%) \\ 51-55 & 4(2.84 \%) & 2(50.00 \%) & 2(50.00 \%) \\ 56-60 & 5(3.55 \%) & 2(40.00 \%) & 3(60.00 \%) \\ 61-65 & 4(2.84 \%) & 1(25.00 \%) & 3(75.00 \%) \\ 66-70 & 3(2.13 \%) & 2(66.67 \%) & 1(33.33 \%) \\ 71-75 & 2(1.42 \%) & 1(50.00 \%) & 1(50.00 \%) \\ \text { Total } & 141 & 59(41.84 \%) & 82(58.16 \%)\end{array}$

C. Occupation

Applicants

Civil servants

$21(14.89 \%)$

$30(21.28 \%)$

$11(52.38 \%)$

$11(36.67 \%)$

$48(34.04 \%)$

Traders

$42(29.79 \%)$

$21(43.75 \%)$

$16(38.09 \%)$

Students

141

$59(41.84 \%)$

$10(47.62 \%)$

$19(63.33 \%)$

$27(56.25 \%)$

$26(61.90 \%)$

Total

D. Education status

Primary

Secondary

Tertiary

$67(47.52 \%)$

$49(34.75 \%)$

$25(37.31 \%)$

$24(48.98 \%)$

$10(40.00 \%)$

Total

$25(17.73 \%)$

$59(41.84 \%)$

$82(58.16 \%)$

E. Marital status

$\begin{array}{cccc}\text { Married } & 47(33.33 \%) & 18(38.29 \%) & 29(61.70 \%) \\ \text { Single } & 39(27.66 \%) & 18(46.15 \%) & 21(53.85 \%) \\ \text { Divorced } & 26(18.44 \%) & 12(46.15 \%) & 14(53.85 \%) \\ \text { ow / Widower } & 29(20.57 \%) & 11(37.93 \%) & 18(62.07 \%) \\ \text { Total } & 141 & 59(41.84 \%) & 82(58.16 \%)\end{array}$

Table 2. Prevalence of malaria infections in Abagana community.

\begin{tabular}{lcccccc}
\hline Personal data & No. & No. & No. males & No. males & No. females & No. females \\
& examined & positive $(\%)$ & examined & positive $(\%)$ & examined & positive $(\%)$ \\
\hline
\end{tabular}

A .Village

$\begin{array}{llrrrrr}\text { Adagbe } & 30 & 17(56.67 \%) & 13(43.33 \%) & 7(53.85 \%) & 17(56.67 \%) & 10(58.82 \%) \\ \text { Akpu } & 33 & 20(60.61 \%) & 13(39.39 \%) & 8(61.54 \%) & 20(60.61 \%) & 12(60.00 \%) \\ \text { Amaenye } & 23 & 13(56.52 \%) & 10(43.48 \%) & 6(60.00 \%) & 13(56.52 \%) & 7(53.85 \%) \\ \text { Orofia } & 21 & 8(38.09 \%) & 8(38.09 \%) & 3(37.50 \%) & 13(61.90 \%) & 5(38.46 \%) \\ \text { Umudunu } & 19 & 8(42.11 \%) & 9(47.37 \%) & 4(44.44 \%) & 10(52.63 \%) & 4(40.00 \%) \\ \text { Uruokpala } & 15 & 10(66.67 \%) & 6(40.00 \%) & 4(66.67 \%) & 9(60.00 \%) & 6(66.67 \%) \\ \text { Total } & 141 & 76(53.90 \%) & 59(41.84 \%) & 32(42.11 \%) & 82(58.16 \%) & 44(53.66 \%)\end{array}$

\begin{tabular}{|c|c|c|c|c|c|c|}
\hline \multicolumn{7}{|l|}{ B .Age group } \\
\hline $0-5$ & 11 & $10(90.91 \%)$ & $4(36.36 \%)$ & $3(75.00 \%)$ & $7(63.67 \%)$ & $6(85.11 \%)$ \\
\hline $6-10$ & 12 & $8(66.67 \%)$ & $5(41.67 \%)$ & $3(60.00 \%)$ & $7(58.33 \%)$ & $5(71.43 \%)$ \\
\hline $11-15$ & 13 & $7(53.85 \%)$ & $5(38.46 \%)$ & $3(60.86 \%)$ & $8(61.54 \%)$ & $4(50.00 \%)$ \\
\hline $16-20$ & 18 & $6(33.33 \%)$ & $8(44.44 \%)$ & $2(25.00 \%)$ & $10(55.56 \%)$ & $4(40.00 \%)$ \\
\hline
\end{tabular}


Stable endemic malaria in a rainforest community of Southeastern Nigeria

\begin{tabular}{ccccccc}
\hline $21-25$ & 15 & $4(26.67 \%)$ & $6(40.00 \%)$ & $2(33.33 \%)$ & $9(60.00 \%)$ & $2(22.22 \%)$ \\
$26-30$ & 19 & $5(26.32 \%)$ & $8(42.11 \%)$ & $2(25.00 \%)$ & $11(57.89 \%)$ & $3(27.27 \%)$ \\
$31-35$ & 10 & $8(80.00 \%)$ & $5(50.00 \%)$ & $4(80.00 \%)$ & $5(50.00 \%)$ & $3(60.00 \%)$ \\
$36-40$ & 20 & $11(55.00 \%)$ & $9(45.00 \%)$ & $5(55.56 \%)$ & $11(55.00 \%)$ & $6(54.55 \%)$ \\
$41-50$ & 5 & $4(80.00 \%)$ & $1(20.00 \%)$ & $1(100 \%)$ & $3(60.00 \%)$ & $2(66.67 \%)$ \\
$51-55$ & 4 & $3(75.00 \%)$ & $1(25.00 \%)$ & $1(100 \%)$ & $3(50.00 \%)$ & $2(66.67 \%)$ \\
$56-60$ & 5 & $4(80.00 \%)$ & $1(225.00 \%)$ & $1(100 \%)$ & $3(60.00 \%)$ & $2(66.67 \%)$ \\
$61-65$ & 4 & $3(75.00 \%)$ & $2(50.00 \%)$ & $2(100 \%)$ & $1(25.00 \%)$ & $1(100 \%)$ \\
$66-70$ & 3 & $2(66.67 \%)$ & $2(66.67 \%)$ & $2(100 \%)$ & $2(66.67 \%)$ & $1(50.00 \%)$ \\
$71-75$ & 2 & $1(50.00 \%)$ & $2(50.00 \%)$ & $1(100 \%)$ & $3(150 \%)$ & $2(66.67 \%)$ \\
Total & 141 & $76(53.90 \%)$ & $59(41.84 \%)$ & $32(42.11 \%)$ & $82(58.16 \%)$ & $44(57.89 \%)$ \\
\hline
\end{tabular}

C. Occupation

\begin{tabular}{|c|c|c|c|c|c|c|}
\hline Applicants & 21 & $13(61.90 \%)$ & $11(52.38 \%)$ & $6(54.55 \%)$ & $10(47.62 \%)$ & $7(70.00 \%)$ \\
\hline Civil servants & 30 & $12(40.00 \%)$ & $11(36.67 \%)$ & $4(36.36 \%)$ & $19(63.33 \%)$ & $8(42.11 \%)$ \\
\hline Traders & 48 & $26(54.17 \%)$ & $21(43.75 \%)$ & $12(57.14 \%)$ & $27(56.25 \%)$ & $14(51.85 \%)$ \\
\hline Students & 42 & $25(59.52 \%)$ & $16(38.09 \%)$ & $10(62.50 \%)$ & $26(61.90 \%)$ & $15(57.69 \%)$ \\
\hline Total & 141 & $76(53.90 \%)$ & $59(41.84 \%)$ & $32(42.11 \%)$ & $82(58.16 \%)$ & $44(57.89 \%)$ \\
\hline \multicolumn{7}{|l|}{$\begin{array}{l}\text { D. Education } \\
\text { status }\end{array}$} \\
\hline Primary & 67 & $39(58.21 \%)$ & $25(37.31 \%)$ & $16(64.00 \%)$ & $42(62.69 \%)$ & $23(57.14 \%)$ \\
\hline Secondary & 49 & $26(53.06 \%)$ & $24(48.97 \%)$ & $12(50.00 \%)$ & $25(51.02 \%)$ & $14(60.00 \%)$ \\
\hline Tertiary & 25 & $11(44.00 \%)$ & $10(40.00 \%)$ & $4(40.00 \%)$ & $15(60.00 \%)$ & $7(46.67 \%)$ \\
\hline Total & 141 & $76(53.90 \%)$ & $59(41.84 \%)$ & $32(42.11 \%)$ & $82(58.16 \%)$ & $44(57.89 \%)$ \\
\hline \multicolumn{7}{|l|}{$\begin{array}{l}\text { E. Marital } \\
\text { Status }\end{array}$} \\
\hline Married & 47 & $17(36.17 \%)$ & $18(38.29 \%)$ & $7(38.89 \%)$ & $29(61.70 \%)$ & $10(34.48 \%)$ \\
\hline Single & 39 & $19(48.72 \%)$ & $17(43.59 \%)$ & $7(41.18 \%)$ & $22(56.41 \%)$ & $12(54.55 \%)$ \\
\hline Divorced & 26 & $18(69.23 \%)$ & $13(50.00 \%)$ & $9(63.23 \%)$ & $13(50.00 \%)$ & $9(69.23 \%)$ \\
\hline $\begin{array}{l}\text { Widow / } \\
\text { Widower }\end{array}$ & 29 & $22(75.86 \%)$ & $11(37.93 \%)$ & $9(81.82 \%)$ & $18(62.07 \%)$ & $13(72.22 \%)$ \\
\hline Total & 141 & $76(53.90 \%)$ & $59(41.84 \%)$ & $32(42.11 \%)$ & $82(58.16 \%)$ & $44(57.89 \%)$ \\
\hline
\end{tabular}

Table 3. Intensity of malaria infection in relation to personal data.

\begin{tabular}{|c|c|c|c|c|c|}
\hline \multirow[t]{2}{*}{ Personal data } & \multirow[t]{2}{*}{ No. examined } & \multirow[t]{2}{*}{ No. positive (\%) } & \multicolumn{3}{|c|}{ Intensity of malaria infection (\%) } \\
\hline & & & Light $(+)$ & Moderate $(++)$ Hea & $-++)$ \\
\hline \multicolumn{6}{|l|}{ A. Village } \\
\hline Adagbe & 30 & $17(56.67 \%)$ & $8(47.06 \%)$ & $7(41.18 \%)$ & $2(11.76 \%)$ \\
\hline Akpu & 33 & $20(60.61 \%)$ & $9(45.00 \%)$ & $8(40.00 \%)$ & $3(15.00 \%)$ \\
\hline Amaenye & 23 & $13(56.52 \%)$ & $6(46.15 \%)$ & $6(46.15 \%)$ & $1(7.69 \%)$ \\
\hline Orofia & 21 & $8(38.09 \%)$ & $3(37.50 \%)$ & $3(37.50 \%)$ & $2(25.00 \%)$ \\
\hline Umudunu & 19 & $8(42.11 \%)$ & $2(25.00 \%)$ & $5(62.50 \%)$ & $1(12.50 \%)$ \\
\hline Uruokpala & 15 & $10(66.67 \%)$ & $4(40.00 \%)$ & $6(60.00 \%)$ & $0(0 \%)$ \\
\hline Total & 141 & $76(53.90 \%)$ & $32(42.11 \%)$ & $35 \quad 46.05 \%)$ & $9(11.84 \%)$ \\
\hline \multicolumn{6}{|l|}{ B. Gender } \\
\hline Male & 59 & $32(54.24 \%)$ & $17(53.13 \%)$ & $10(31.25 \%)$ & $5(15.23 \%)$ \\
\hline Female & 82 & $44(53.66 \%)$ & $15(34.09 \%)$ & $25(56.82 \%$ & $4(9.09 \%)$ \\
\hline \multicolumn{6}{|l|}{$\begin{array}{l}\mathrm{C} \text {.Age } \\
\text { group }\end{array}$} \\
\hline $0-5$ & 11 & $10(90.91 \%)$ & $3(30.00 \%)$ & $4(40.00 \%)$ & $2(22.22 \%)$ \\
\hline $6-10$ & 12 & $8(66.67 \%)$ & $3(37.50 \%)$ & $4(50.00 \%)$ & $1(12.50 \%)$ \\
\hline $11-15$ & 13 & $7(53.85 \%)$ & $3(42.86 \%)$ & $3(42.86 \%)$ & $1(12.50 \%)$ \\
\hline $16-20$ & 18 & $6(33.33 \%)$ & $4(66.67 \%)$ & $2(33.33 \%)$ & $0(0 \%)$ \\
\hline $21-25$ & 15 & $4(26.67 \%)$ & $1(25.00 \%)$ & $3(75.00 \%)$ & $0(0 \%)$ \\
\hline $26-30$ & 19 & $5(26.32 \%)$ & $3(60.00 \%)$ & $2(40.00 \%)$ & $0(0 \%)$ \\
\hline $31-35$ & 10 & $8(80.00 \%)$ & $3(37.50 \%)$ & $3(37.50 \%)$ & $1(14.29 \%)$ \\
\hline $36-40$ & 20 & $11(55.00 \%)$ & $3(27.27 \%)$ & $6(54.55 \%)$ & $2(18.18 \%)$ \\
\hline $41-50$ & 5 & $4(80.00 \%)$ & $2(50.00 \%)$ & $2(50.00 \%)$ & $0(0 \%)$ \\
\hline $51-55$ & 4 & $3(75.00 \%)$ & $2(66.67 \%)$ & $1(33.33 \%)$ & $0(0 \%)$ \\
\hline $56-60$ & 5 & $4(80.00 \%)$ & $1(25.00 \%)$ & $2(50.00 \%)$ & $0(0 \%)$ \\
\hline
\end{tabular}


Stable endemic malaria in a rainforest community of Southeastern Nigeria

\begin{tabular}{|c|c|c|c|c|c|}
\hline $\begin{array}{c}61-65 \\
66-70 \\
71-75 \\
\text { Total } \\
\end{array}$ & $\begin{array}{r}4 \\
3 \\
2 \\
141 \\
\end{array}$ & $\begin{array}{c}3(75.00 \%) \\
2(66.67 \%) \\
1(150 \%) \\
76(53.90 \%) \\
\end{array}$ & $\begin{array}{c}2(66.67 \%) \\
1(50.00 \%) \\
1(100 \%) \\
32(42.11 \%) \\
\end{array}$ & $\begin{array}{c}2(66.67 \%) \\
1(50.00 \%) \\
0(0 \%) \\
35(46.05 \%) \\
\end{array}$ & $\begin{array}{l}0(0 \%) \\
1(33.33 \%) \\
1(50.00 \%) \\
9(11.84 \%) \\
\end{array}$ \\
\hline D.Occupation & & & & & \\
\hline $\begin{array}{c}\text { Applicants } \\
\text { Civil servants } \\
\text { Traders } \\
\text { Students } \\
\text { Total } \\
\end{array}$ & $\begin{array}{c}21 \\
30 \\
48 \\
42 \\
141 \\
\end{array}$ & $\begin{array}{l}13(61.90 \%) \\
12(40.00 \%) \\
26(54.17 \%) \\
25(59.52 \%) \\
76(53.90 \%) \\
\end{array}$ & $\begin{array}{c}3(23.08 \%) \\
7(58.33 \%) \\
9(34.62 \%) \\
13(52.00 \%) \\
32(42.11 \%) \\
\end{array}$ & $\begin{array}{r}7(53.85 \%) \\
5(41.67 \%) \\
13(50.00 \%) \\
10(40.00 \%) \\
35(46.05 \%) \\
\end{array}$ & $\begin{array}{l}3(23.08 \%) \\
0(0 \%) \\
4(15.38 \%) \\
2(8.00 \%) \\
9(11.84 \%) \\
\end{array}$ \\
\hline $\begin{array}{c}\text { E. Education } \\
\text { Status } \\
\text { Primary } \\
\text { Secondary } \\
\text { Tertiary } \\
\text { Total } \\
\end{array}$ & $\begin{array}{r}67 \\
49 \\
25 \\
141 \\
\end{array}$ & $\begin{array}{c}39(58.21 \%) \\
26(53.06 \%) \\
11(44.00 \%) \\
76(53.90 \%) \\
\end{array}$ & $\begin{array}{r}15(38.46 \%) \\
12(46.15 \%) \\
5(45.45 \%) \\
32(42.11 \%) \\
\end{array}$ & $\begin{array}{r}20(51.28 \%) \\
11(42.31 \%) \\
4(36.36 \%) \\
35(46.05 \%) \\
\end{array}$ & $\begin{array}{l}4(10.26 \%) \\
3(11.54 \%) \\
2(18.18 \%) \\
9(11.84 \%) \\
\end{array}$ \\
\hline $\begin{array}{c}\text { F. Marital status } \\
\text { Married } \\
\text { Single } \\
\text { Divorced } \\
\text { Widow / Widower } \\
\text { Total } \\
\end{array}$ & $\begin{array}{c}47 \\
39 \\
26 \\
29 \\
141 \\
\end{array}$ & $\begin{array}{l}17(36.17 \%) \\
19(48.72 \%) \\
18(69.23 \%) \\
22(75.86 \%) \\
76(53.90 \%) \\
\end{array}$ & $\begin{array}{c}9(52.94 \%) \\
7(36.84 \%) \\
10(55.56 \%) \\
6(27.27 \%) \\
32(42.11 \%) \\
\end{array}$ & $\begin{array}{r}7(41.18 \%) \\
10(52.63 \%) \\
6(33.33 \%) \\
12(54.55 \%) \\
35(46.05 \%) \\
\end{array}$ & $\begin{array}{l}1(5.88 \%) \\
2(10.53 \%) \\
2(11.11 \%) \\
4(18.18 \%) \\
9(11.84 \%) \\
\end{array}$ \\
\hline
\end{tabular}

Legend

Light $(+)=1-10$ parasites per 100 high power field. Moderate $(++)=11-100$ parasites per 100 high power field. Heavy $(+++)=1-10$ parasites in every high power field. More than 10 parasites in every high power field $(++++)$ (Cheesbrough, 2004).

\section{Discussion And Conclusion}

There was unequal representation of participants from the villages, sexes, age groups, educational and marital groups. This is consistent with the work of [19], who in their study, had the highest participants among the age group of 41-50 years. Lack of knowledge about the consequences of malaria transmission might account for the low turnout among some members of these groups [20], noted that the low level of awareness among different occupational groups affects their participation in free medicare. Similar results were reported by [21] in Tanzania, who in his study attributed this to attitude of the females to seek adequate medical care than the males. In Abagana, community most men leave their wives and children in the villages and travel to the cities in search of greener pastures.

Of the 141 participants, only 51(36.17\%) were below 21 years of age while 90(63.83\%) were aged 21 years and above. This shows that a large number of the participants were adults that could appreciate the programme and participate responsibly. Also, they were made up of people with varying educational and occupational status. In a similar study at Enugu, [22] noted that among the residents of Ugbo-Odogwu area, the majority of the participants were aged above 20 years, about $62.5 \%$, had primary education, $25 \%$ secondary education, $8.75 \%$ tertiary education and $3.75 \%$ non-formal education, they concluded that they were old and literate enough to benefit from any co-ordinated community directed health programme.

A high prevalence of malaria parasitaemia $76(53.90 \%)$ was observed among the study group. This shows that malaria is an endemic parasitic disease in Abagana town irrespective of the fact that majority of the participants were apparently healthy individuals at the time of the study. This result was in accordance with the findings of [12] who reported malaria prevalence of 59.80\% in Udi community in Enugu State, south-eastern Nigeria, [23] who reported a high malaria prevalence of 62.0\% in Umudioka community in Anambra State of Nigeria and [24] who observed a malaria prevalence of 58.30\% among school children in Awka. In contrast with these, [25] obtained prevalence rate of $6.0 \%$ among apparently healthy blood donor population studied in Maiduguri, north-eastern Nigeria. This wide range of difference may be attributed to the differences in climatic factors which promote mosquito breeding and also to human behavioural patterns and immunity which enhances susceptibility of the people to infections.

Malaria infections were detected in both males and females who participated in the study with the females having slightly higher prevalence $44(53.66 \%)$ than the males $32(42.11 \%)$. Although the females had slightly higher malaria prevalence than the males, the result was not statistically significant. This is consistent with the findings of [26], who observed a relatively higher prevalence rate of 44(31.21\%) among the females 
than their male counterparts who had a prevalence rate of 32(22.69\%). Also [27] observed that non- clinically ill females showed significantly higher malaria prevalence $(64.4 \%)$ than their male counterparts $(60.9 \%)$ at Ikwuano, Abia State. These findings agree with that of [28], who observed that females are at higher risk of malaria infection when compared to their male counterparts. Females often stay out late during mosquito biting hours carrying out domestic activities. It could also be that the males have better immunity to malaria infection due to proper nutritional standard and prompt treatment on the slightest episode of the disease.

Malaria infection was observed in all the fourteen age groups studied, with the age group $0-5$ years having the highest prevalence of $10(90.91 \%)$ and the least prevalence of 5(26.32\%) among the age group of 26 - 30 years. [24] observed malaria prevalence of $58.0 \%$ in children aged 0-5 years in Awka, Anambra State, Nigeria, which a few kilometers away from Abagana. [29] observed that children within 1-6 years of age had a higher risk of being reported with malaria than other age groups among travelers in Sweden. Similar observations were made by [30] and United Nations Agency for International Development [31]. This result is consistent with the finding of [32], who studied age-related pattern of transmission of the disease and attributed the differences in malaria infection among the age groups to the level of immunological response of the host including differential activities of the age groups. They noted that people in the older age groups apply preventive measures against mosquito bites as a result of their knowledge of the mode of malaria transmission. Immunity in the younger age groups as in the age group $0-5$ years is lower but as the age increased, stronger immunity for the disease is built up as a result of frequent exposure to the ailment, hence lower prevalence among adult groups.

Malaria infection was also detected in the four occupational groups with the highest prevalence of $13(61.90 \%)$ among the applicants and the least prevalence of $12(40.00 \%)$ among the civil servants. The high prevalence of malaria among applicants could be attributed to poverty. [33] studied the relationship between occupation and malaria infection and observed a significantly higher prevalence of the Plasmodium parasite in low paid, industrial or unskilled workers or the unemployed than in a high category (civil servants). [34], noted that in addition to abundant breeding sites in the villages, ignorance, poverty, unsanitary conditions, poor behavioural attitudes and inadequately planned socio-economic projects tends to increase malaria transmission in the rural areas. [25] noted that poor farmers derived from low socio-economic status, with inadequate housing facilities and financial constraints are unable to engage in malaria preventive and control measures. They are also unable to purchase effective anti-malarial drugs.

Malaria infection was found in all the educational groups with the highest prevalence of 39(58.21\%) among the primary education group and the least prevalence of 11(44.00\%) among the tertiary education group. Education improves general awareness of disease causation and prevention and it could be that those who have tertiary education had better understanding on how to protect themselves from mosquito bites and disease transmissions. This study corroborates with the findings of [35], who obtained least malaria prevalence among those with tertiary education and attributed this to their high awareness as a result of their educational background. [34] obtained high malaria prevalence among those with primary and non-formal education groups and attributed it to lack of knowledge about malaria infection and prevention.

Malaria infection was observed in all the marital groups with the highest prevalence of 22(75.86\%) among the widows and widowers and the least prevalence of 17(36.17\%) among the married groups that were still living together. Living alone, lower standard of living, education and living arrangement have been greatly associated with an increase in malaria prevalence. [36] observed similar differences in malaria prevalence among different marital groups and particularly noted that widows/widowers suffer from malaria three times more than the couples living together.

Malaria infections were observed in all persons from different areas of Abagana, suggesting endemicity of the disease irrespective of the fact that the participants were apparently healthy. This result also indicates that malaria transmission is widespread in Abagana community, probably the ecological and climatic conditions are very suited for easy transmission of the malaria in the area. Such clustering is consistent with the observed tendency for Anopheles mosquitoes to over disperse [37]. Recently, several authors focused attention on urban malaria [38] and stressed the need to investigate risk factors for urban malaria. Although levels of transmission in urban areas may be lower than in contiguous rural areas, high population densities and possible lower immunity [39] may result in more disease impact in urban settings.

Light and moderate malaria infections accounted for $67(88.16 \%)$ of the malaria prevalence in the community while heavy infections were responsible for only $9(11.84 \%)$, not minding the fact that most of the participants were apparently healthy and hence asymptomatic at the onset of this study. [40], described "Stable Endemic Malaria" as a situation where members of a holo-endemic population remain asymptomatic even with considerably high levels of malaria parasitaemia. Part of this may be the reason for the result. This high intensity underscores the fact that, malaria is still a heavy burden on the continent, despite all that has been done.

The results also showed that the highest intensity of malaria was in the age groups 71-75 years, followed by age groups 66-70 years. The high intensity of malaria infections in adults in this study suggests that 
these persons have lost some degree of immunity as a result of poor living conditions in addition to life long exposure [41]. Also, children born to immune mothers are protected against the disease (malaria) during their first half year of life by maternal antibodies but as they grow older, after continued exposure from multiple malaria infections over time, they build up an acquired immunity and become relatively protected against the disease [42].

Malaria intensity was least among married participants living together than the singles, widows/widowers and divorcees. [44] observed that there was a statistically significant relationship between malaria intensity and marital status. He attributed the high intensity of malaria infection of widows/widowers to their complacent approach in seeking adequate medical care at the onset of malaria manifestation while they usually resort to herbal medicine which they feel is much cheaper and affordable, but are incapable of clearing parasites more effectively.

The findings of the present study have revealed holoendemicity of malaria infection in the six villages of Abagana community, Southteastern, Nigeria affecting all ages, occupation and educational groups. Intervention efforts including massive educational campaigns, construction of drainage, use of preventive measures such as sleeping under long lasting insecticide nets (LLINs) and treatment of affected individuals with artemisinin combination therapies (ACTs) are highly recommended to protect the citizens from serious malaria attacks.

\section{Acknowledgements}

The authors are grateful to the staff of Community Health Centre, Abagana, Anambra State, Nigeria for assisting us in the sample collection. The contribution of (Dr) A.E. Onyido to the study is greatly acknowledged.

\section{References}

[1] D. Warrell, Pathophysiology of severe falciparum malaria in man. Symposia of the British Society of Parasitology, Parasitology. 24(94), 1987, S53-S76.

[2] J. Sahr, Malaria and its effect on vertebrate host. J. Clin. Med., (21), 2000, 97-202.

[3] A.V. Kondrachine, and P.T.Trigg, The current global malaria situation 11-12 in Sherman ed. Malaria parasite biology, pathogenesis and protection. ASM press. (Washington DC, 1997) 123-126.

[4] WHO, Making every mother and child count. World Health Organization, Geneva. The World Health Report., 2005a

[5] I. Sherman, A brief history of malaria and discovery of the parasite lifecycle. In malaria parasite biology, pathogenesis and protection. Sherman I.W.ed. (ASM press, Washington DC. 1998) 347-353.

[6] Roll Back Malaria, Facts about malaria in Nigeria,Abuja.Publication on the Roll Back Malaria, 2005, 1-2.

[7] Federal Ministry of health, National Treatment Guidelines Federal Ministry of Health. Publication of the FMH, Nigeria, $2005 \mathrm{a}, 44$.

[8] F. Ukoli, The Biology and natural history of malaria. Proceedings of the annual convention and scientific assembly. Archives of Ibadan medicine 1(2), 2003, 35-36.

[9.] K. Abdullahi., U. Abubakar., and T. Adamu, Malaria in Sokoto,North western Nigeria., African Journal of Biotechnology, 8(24), 2009, 7101-7105.

[10] B. Uzochukwu, and O. Onwujekwe, Socio-economic differences and health seeking behaviour for the diagnosis and treatment of malaria: a case study of four local government areas operating the Bamako initiative programme in south- east Nigeria., International Journal for Equity in Health, 2001.

[11] WHO, International Workshop, Intensified Control of Neglected Diseases, World Health Organization, Summary Report, 10-12 December 2003. /http://whqlibdoc.who.int/ hq/2004/WHO_CDS_CPE_CEE_2004.45, 2003.

[12] C. Eneanya, Seasonal variation in malaria episodes among residents in Udi, a semi-urban community in southeast, Nigeria, The Nigerian journal of Parasitology Volume 9, 1998, $39-43$.

[13] N. Iloeje, A new geography of Nigeria, new revised edition. Longman Nigeria PLC, Ikeja 199pp. ISBN 0582 60396X (Nigerian edition, 2001) 345-347.

[14] National Population Commission, Population Census of Nigeria. Population distribution in Local Government Areas by Sex and Number of Households, 1991.

[15] T.T. Epidi, C.D. Nwani, and N.P. Ugorji, Prevalence of malaria in blood donors in Abakaliki Metropolis, Nigeria, Scientific Research and Essay (3), 2008, 162-164.

[16] M. Cheesebrough, District laboratory practice in tropical countries. Part 2. (Cambridge University Press, 2004$), 357$.

[17] S.L. Feck, and A.H. Moody, Characteristics of malaria parasites. In: Diagnostic Techniques in Medical Parasitology, $1^{\text {st }}$ edition, (Butterworth Publishers London, 1988) 5-15.

[18] A.E. Ogbeibu, Biostatistics: A practical approach to research and data handling. Mindex Publishing company Limited, Benin city. (2), 2005, 302-306.

[19] O.M. Ukpai, and E.I. Ajoku, E.I, The prevalence of malaria in Okigwe and Owerri Areas of Imo state, The Nigerian J. of Parasitology, 22 (192), 2001, 43-48.

[20] Centre for Disease Control, Division of malaria Elimination. Multi - drug Resistant Malaria. Retrieved from http://www.cdc.gov/malaria/pubs/malariafactsheets/mdrtb.htm on 15th April, 2008.

[21] E.M. Mboera, G. Schander, I. Sambou,, and B.M. Greenwood, Suppression of cell-mediated immune response to malaria antigen in pregnant Tanzanian women, American journal of Tropical Medicine and Hygiene; 40, 2006, $141-144$

[22] A.E. Onyido, J. Mamah, O.O. Ikpeze, and C.E. Ononiwu, Dental disorders among residents of Ugbo-Odogwu Escarpment, Udi Hills, Eastern Nigeria, Animal Reseacrh International 3(3), 2006, 534-539.

[23] A.E. Onyido,V.I. Ezike, N.A. Ozumba, E.O. Nwosu, O.O. Ikpeze, M.O. Obiukwu, and E.S. Amadi, Crepuscular man- biting mosquitoes of a tropical Zoological Garden in Enugu, South-East Nigeria, The internet journal of parasitic diseases, 4 (1), 2009a, $1-9$. 
[24] J.I. Mbanugo, and D.O. Ejims, Plasmodium infections in children aged $0-5$ years in Awka metropolis, Anambra state, Nigeria, Nigeria journal of Parasitology; 21, 2000, 55 - 59.

[25] S.G. Ahmed,U.A. Ibrahim,. and G. Ibrahim, Prevalence and clinical significance of malaria parasitaemia in blood donors in Maiduguri, Nigeria. The Nigerian journal of Parasitology; 22(1and2), 2001, $29-34$

[26] B.K. Mandal, and M.R.J. White, Lecture notes on infectious Diseases, 4th edition.( Blackwell Scientific Publication, 1984) 172195.

[27] E.T. Oparaocha, The impact of haemoglobin level and concomitant infections on malaria parasitaemia and onset of fever during malaria attack at Ikwuano Local Government Area of Abia State, Nigeria, The Nigerian journal of Parasitology, 24, 2003, 25-32.

[28] K.S. Warren, and A.F. Mahmoud, Malaria. In:Tropical Geographical Medicine. 2nd Edin. (McGraw Hill Co, 1990). 263-295.

[29] H.H. Askling., J. Nilsson, and A. Tegnell, Malaria risk in travelers, Emerging Infectious Diseases, 11(3), $2005,436-441$.

[30] World Health Organization, Malaria epidemics: forecasting, prevention, early detection and control-from policy to practice. Geneva: The Organization; 2004. Available from http://www.who.int/malaria/docs/Leysinreport.pdf

[31] United Nations Programme on HIV/AIDS/ World Health Organization (UNAIDS/WHO), Global Facts and Figures. AIDS epidemic update December 2009

[32] C.P. Pant, M. Rishikesh, Y.H. Bang, and A. Smith, Progress in malaria vector control, Bulletin of World Health Organisation; 59(3), 1981, 305-492.

[33.] J.G. Tshikuka, M.E. Scott, K. Gray-Donald,. and O.N. Kalumba, Multiple infection with Plasmodium and helminths in communities of low and relatively high socio-economic status, Ann Trop Med Parasitol 90, 1996, 277-93.

[34] G.G. . Ejezie, The Nigerian Environment and Parasitic infections. Folia parasite (PRAHA).30, 1983, 80-95.

[35] W.R. Brieger, E. Nwankwo, V.I. Ezike, J.D. Sexton, J.G. Breman, S.A. Parker, O.J.. Ekanem, and T. Robinson, Social and behavioural baseline for implementation of an efficacy trial of insecticide treated bednets for malaria control at Nsukka. International Quarterly, Journal of community Health Education.16(1), 1997, 17-61.

[36] M.A. Chen, Why widowhood matters? United Nations publications, (New York, 1995), 99-105.

[37] E. Klinkenberg, P.J. Mccall, and I.M. Hastings, Malaria and irrigated crops,Accra,Ghana., Emerging Infections Diseases, 11(8), 2005, 1290-1293.

[38] V. Robert, K. Macintyre, J. Keating,, J.F. Trape, J.B. Duchemin,, and M. Warren, Malaria transmission in urban sub-Saharan Africa, American Journal of Tropical of Medicine and Hygiene, 68, 2003, 169-176.

[39] J.F. Trape, and A. Zoulani, Malaria and urbanization in central Africa: the example of Brazzaville. Part III: Relationships between urbanization and the intensity of malaria transmission, Transactions of the Royal Society of Tropical Medicine and Hygiene 81, 1987, 19-25.

[40] C.J. Thomas, G. Davies, and C.E. Dunn, Mixed picture for changes in stable malaria distribution with future climate in Africa, Trends Parasitol. 20, 2004, 216-220.

[41] P. Perlmann, and M. Troye-Blomberg, Malaria Immunology. Perlmann P and Troye-Blomberg, M. (editors). Basel, Krager, 80, 2000, 229-242

[42] M. Plebanski, and A.V. Hill,(2000). The Immunology of Malaria Infection, Curr. Opin. Immunol. 12(4), $2000,437-441$. 